\title{
RANCANG BANGUN SISTEM BUOY MENGGUNAKAN SISTEM KOMUNIKASI LONG RANGE UNTUK PENGAMATAN WILAYAH PESISIR
}

\author{
SATRIA MITRA UTAMA*, ACHMAD MAULANA RAFI, JUSTINUS RISTOADI, \\ HARIYANTO \\ Prodi Instrumentasi, \\ Sekolah Tinggi Meteorologi Klimatologi dan Geofisika \\ Jl. Perhubungan 1 No.5 Pondok Betung, Pondok Aren. \\ *email : satriamitra@hotmail.com
}

\begin{abstract}
Abstrak. Indonesia adalah negara maritim dengan wilayah perairan yang luas. Wilayah perairan yang luas menyebabkan observasi maritim menjadi terhambat. Selama ini aktivitas observasi masih dilakukan dengan bantuan kapal, sehingga membutuhkan biaya yang tinggi dan dan tidak efisian. Padahal parameter kelautan seperti suhu laut bermanfaat bagi kegiatan manusia dibidang keselamatan transportarsi maupun kepentingan ilmiah. Badan Meteorologi Klimatologi dan Geofisika (BMKG) sebagai lembaga pemerintah bertugas melakukan observasi maritime parameter suhu laut. Data suhu laut didapatkan dari citra satelit dan permodelan Ocean Forecasting System (OFS) BMKG dikarenakan keterbatasan alat dan biaya untuk melakukan pengamatan secara langsung. Makalah ini bertujuan untuk mengatasi permasalahan dengan merancang sistem Buoy yang dapat beroperasi dengan mudah dan efisien. Komponen yang digunakan dalam penelitian ini yaitu berupa sensor waterproof DS18B20, mikrokontroler ATmega 328P dan sistem komunikasi Long Range (LoRa). Data pengamatan Buoy dikirimkan secara realtime. Sistem komunikasi LoRa menunjukan mampu untuk mengirimkan data hingga jangkauan $2 \mathrm{Km}$ dengan kondisi tanpa ada penghalang. Data pengamatan lalu ditampilkan pada sistem antarmuka.
\end{abstract}

Kata kunci :Mikrokontroler, Buoy, LoRa, realtime

\begin{abstract}
Indonesia is a maritime country with a vast water territorial. The vast marine areas cause maritime observations to be inhibited. During this observation activity is still done with the ship, so it's become high cost and not efficient. Whereas marine parameters such as sea temperature is beneficial to human activities in the field of transportation safety and scientific interests. Indonesian Agency of Meteorology, Climatology, and Geophysics (BMKG) as a government agency is in charge to do an observation in maritime sea temperature parameters. The data are obtained from satellite imagery and BMKG's Ocean Forecasting System (OFS) modelling, due to the limited equipment and the cost to do a direct observation. The goals of this paper are to overcome problems by designing a Buoy system that can operate easily and efficiently. The components used in this research are waterproof DS18B20 sensor, microcontroller ATMega328P and Long-Range communication system (LoRa). Buoy's observation data is delivered real-time. LoRa communication system is capable to transmit data up to $2 \mathrm{~km}$ without any obstacles conditions. And then the observed data will be displayed on the interface system.
\end{abstract}

Keywords :Mikrokontroler, Buoy, LoRa, realtime

\section{Pendahuluan}

Wilayah perairan yang luas inilah potensi terbesar yang dimiliki Indonesia untuk memajukan perekonomian nasional. Perekonomian Indonesia sangat dipengaruhi 
oleh kondisi kelautan. Sektor-sektor yang berpotensi di bidang kelautan antarai lain seperti sektor perikanan, pariwisata bahari, perhubungan laut dan jasa kelautan [1].

Badan Meteorologi Klimatologi dan Geofisika (BMKG) merupakan lembaga pemerintah yang mempunyai tugas pokok untuk melakukan pengamatan di bidang Meteorologi, Klimatologi, Kualitas Udara dan Geofisika (MKKuG). Salah satu uraian tugas pokok BMKG yaitu melakukan observasi meteorologi maritim. Pengamatan meteorologi maritim berfungsi sebagai penyedia informasi Cuaca dan jasa bagi sektor kelautan. Parameter-parameter yang diukur pada observasi maritime beragam seperti pengukuran suhu permukaan laut (SPL), Informasi maritim ini akan bermanfaat jika dapat dimanfaatkan dengan baik.

Suhu Permukaan Laut (SPL) merupakan parameter kelautan yang mempengaruhi fisis laut dunia [2]. Peningkatan kecil pada SPL secara tidak langsung dapat berdampak seperti terjadi pemutihan karang [3] dan kematian organisme laut [4]. Selain itu peningkatan SPL berpengaruh terhadap fenomena El nino/Southern Oscillation (ENSO) yang dikenal dengan istilah El nino. Fenomena El nino di Indonesia akan membuat curah hujan menurun di daerah Indonesia [5].

SPL diukur pada kedalaman rata - rata 1 meter dari permukaan laut. Pengukuran SPL dapat dilakukan dengan metode langsungmenggunakan Buoyatau dengan metode tidak langsung seperti penginderaan jauh menggunakan citra satelit dan dengan bantuan permodelanOcean Forecasting System (OFS). Akan tetapi data yang didapat dari satelit dan permodelan seringkali memiliki nilai error yang lebih tinggi jika dibandingkan dengan pengukuran langsung [6]. Ditinjau dari segi akuisisi data, pengukuran menggunakan Buоy memiliki kelebihan dalam menghasilkan data secara kontinyu. [7].

Sensor Suhu DS18B20 merupakan sensor yang berfungsi untuk merubah besaran panas menjadi besaran tegangan. Sensor ini berbasis IC DS18B20 yang memiliki presisi tinggi dan tahan terhadap air. Tegangan ideal yang keluar dari DS18B20 bernilai 1 volt pada suhu $100{ }^{\circ} \mathrm{C}$. Nilai keluaran pada sensor suhu DS18B20 berupa nilai yang bersifat digital sehingga tidak diperlukan lagi sebuah perangkat pengubah nilai analog ke nilai digital (ADC) [8].

Long Range (LoRa) Radio adalah suatu teknik modulasi yang unik dan mengagumkan yang dibuat oleh Semtech. modulasi yang dihasilkan menggunakan modulasi FM. Salah satu kelebihan LoRa adalah jarak komunikasi yang jauh antara sistem pengirim dan sistem penerima. LoRa dinilai mampu berkomunikasi hingga jarak $10 \mathrm{Km}[9]$.

Buoy pada prinsipnya adalah sebuah alat yang mengapung diatas permukaan air yang kemudian diikat pada sebuah jangkar. Umumnya Buoy tertambat terdiri dari dua bagian utama, di atas dan di bawah permukaan air. Bagian atas yang mengapung di permukaan berfungsi sebagai tempat komponen elektronika. Sedangkan bagian bawah permukaan Buoy terdapat rantai yang mengikat Buoyke jangkar di dasar perairan.Buoy dilengkapi dengan berbagai macam komponen elektronik seperti sensor suhu untuk mengukur SPL dan juga dilengkapi dengan 
sistem komunikasi untuk mengirimkan data hasil pengamatan sehingga data bisa dilihat secara realtime [10].

Buoydianggap menjadi solusi untuk mengatasi permasalahan ketiadaan Pengukuran SPL secara langsung. Untuk itu perlu dibuat suatu rancangan Buoyyang dilengkapi dengan berbagai macam komponen sehingga dapat bekerja secara mandiri dan berbiaya rendah [11].

Pengukuran SPL memerlukan sensor yang tahan air dan tahan terhadap kondisi ekstrem. Muhammad Iqbal, Indra Jaya, dan Mulia Purba telah merancang drifter Buoymenggunakan sensor DS18B20 yang bersifat waterproof [12]. Sedangkan Trasviña-Moreno dan kawan kawan merancang pesawat tanpa awak untuk pengamatan laut pesisir menggunakan sistem komunikasi LoRa. Hasil pengujian menunjukan bahwa LoRa dapat berkomunikasi hingga jarak 4 Km [13].

Berdasarkan studi yang telah dilakukan diatas, maka peneliti merancang Buoyyang terdiri dari sensor suhu DS18B20 dan dikendalikan oleh mikrokontroler ATmega 328. Data pengamatan Buoy lalu dikirim melalui komunikasi LoRa ke sisi penerima yang berada di daratan. Buoy juga dilengkapi SD Card untuk menyimpan data. Selanjutnya data SPL ditampilkan pada sistem antarmuka.

\section{Metode Penelitian}

Studi awal perancangan Buoy mulai dilakukan bulan Desember 2017 hingga Februari 2018. Perancangan Buoydilakukan di laboratorium Instrumentasi Sekolah Tinggi Meteorologi Klimatologi dan Geofisika (STMKG) di Tangerang Selatan selama bulan Maret hingga Juni. Sedangkan untuk pengkalibrasian sensor DS18B20 dilakukan di Laboratorium Kalibrasi Balai Besar Meteorologi Klimatologi dan Geofisika (BBMKG) Wilayah II Ciputat. Proses pengujian dilakukan di waduk Situ Gintung Ciputat pada bulan Juli 2018.

Desain wahana Buoy dibuat simpel dengan memanfaatkan bahan bahan yang mudah didapatkan. Bahan Utama wahana terdiri dari bola plastik dan pipa pvc. Pipa Pvc sebagai tempat housing atau penyimpanan komponen elektronika ditusuk ke dalam bola plastik hingga menembus sedikit dibagian atas. Lalu dibagian luar dilapisi oleh fiberglass agar wahana kokoh dan tidak tembus air.

Terdapat 2 blok diagram komponen yang digunakan pada penelitian ini, yaitu pada sistem wahana Buoy atau sistem pengirim dan sistem penerima. Komponen elektronik yang digunakan oleh wahana Buoyterdiri dari sensor suhu DS18B20, mikrokontroler ATmega 328, RTC DS3238 sebagai penanda waktu, SD Card dan modul komunikasi LoRa 915MHz. Sedangkan untuk komponen elektronik yang digunakan di sisi penerima hanya mikrokontroler ATmega 328 dan modul komunikasi LoRa $915 \mathrm{MHz}$. 


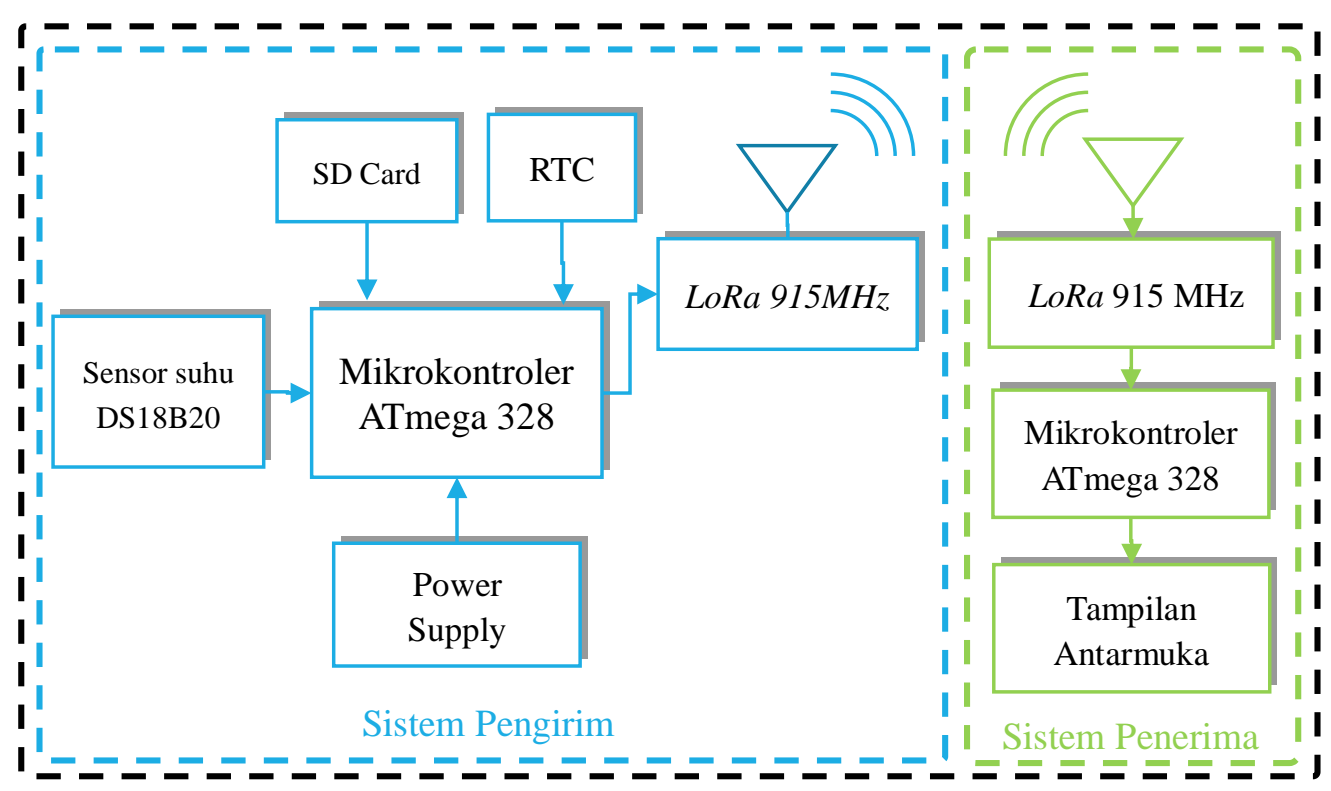

Gambar 1. Blok Diagram Sistem Buoy

Perangkat lunak yang digunakan menggunakan program bersifat open source. Perangkat lunak yang digunakan untuk membuat program Buoyadalah Arduino IDE berbasis Bahasa C. Sedangkan untuk tampilan antarmuka dibuat dengan program Visual Studio.

Kalibrasi bertujuan untuk membandingkan data yang diukur oleh sensor wahana Buoy dengan alat standar yang tertelusur. Hasil kalibrasi diperoleh nilai koreksi pembacaan sensor.

Uji lapang ini terdiri dari uji komunikasi dan uji wahana. Pengujian komunikasi bertujuan untuk mengetahui seberapa jauh jarak antara modul LoRa masih dapat saling berkomunikasi. Uji komunikasi dilakukan di daerah yang bebas dari penghalang seperti pohon dan gedung. Sedangkan Uji wahana yang dilakukan bertujuan untuk mengetahui kemampuan wahana Buoy ketika dilepas di perairan lepas seperti ketahanan wahana, tes kebocoran, daya apung wahana serta kinerja komponen elektronik.

Hasil pengukuran akan dianalisis lebih lanjut dengan menghitung prosentase data yang terkirim oleh Buoyuntuk mengetahui kemampuan komunikasi LoRa. Pengukuran dilakukan dengan interval data setiap menit.

\section{Hasil dan Pembahasan}

Sistem minimum yang digunakan pada penelitian ini menggunakan mikrokontroler berbasis ATmega328. Mikrokontroler ATmega 328 digunakan karena memiliki memiliki bentuk yang kecil sehingga pas ketika dimasukan ke dalam housingpvc. Selain itu konsumsi daya yang rendah sehingga cukup dengan 
menggunakan catu daya dari baterai 9 Volt. Baterai yang terlalu besar dapat berakibat pada daya apung wahana Buoysendiri.

Hasil perancanganBuoy menggunakan bola plastik dan pipa PVC. Di bagian atas Buoysebagai tempatantena transmiter. Mikrokontroler terletak di dalam pipa PVC di bagian dalam bola. Sensor suhu yang terhubung dengan mikrokontroler berada di ujung bawah Buoy dan diletakkan dengan kedalaman 1 meter dibawah permukaan air laut. Data hasil Pengukuran SPLdikirim oleh transmitter dan akan diterima antena oleh receiver dan diteruskan ke PC untuk ditampilkan pada sistem antarmuka. Gambar 2 merupakan desain Buoy pengukur suhu permukaan laut.

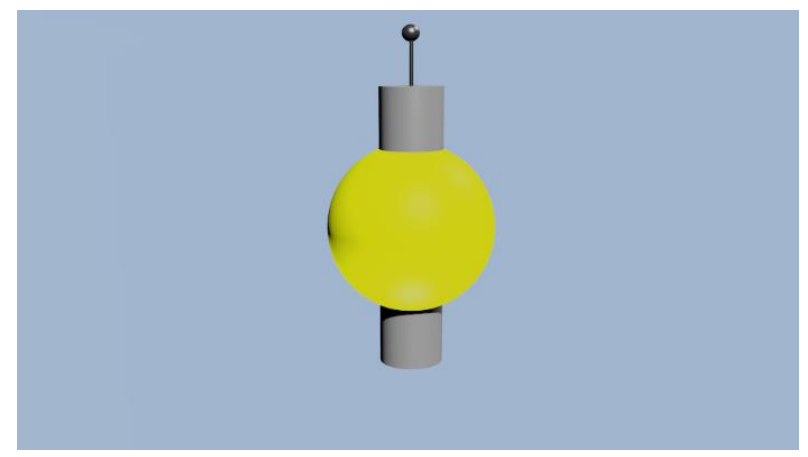

Gambar 2. Desain wahana Buoy

Kalibrasi dilakukan dengan membandingkan sensor suhu DS18B20 dengantermometer standar merek Fluke Hart Scientific. Suhu dikondisikan menjadi 3 set point yaitu pada $20^{\circ} \mathrm{C}, 30^{\circ} \mathrm{C}$ dan $40^{\circ} \mathrm{C}$ dengan menggunakanTemperature Test Chamber merek Theodor Friedrichs \& Co. Pengambilan data dilakukan sebanyak 4 kali setiap set poin setiap 1 menit sekali.. Tabel 1 menunjukkan hasil kalibrasi yang telah dilakukan menggunakan media temperature test chamber.

Tabel 1. Hasil Kalibrasi sensor suhu DS18B20

\begin{tabular}{cccc}
\hline $\begin{array}{c}\text { Suhu Standar } \\
{ }^{\circ} \mathrm{C}\end{array}$ & $\begin{array}{c}\text { Alat yang dikalibrasi } \\
{ }^{\mathbf{o}} \mathbf{C}\end{array}$ & $\begin{array}{c}\text { Koreksi } \\
{ }^{\circ} \mathrm{C}\end{array}$ & $\begin{array}{c}\mathbf{U}_{\mathbf{9 5}} \\
{ }^{\mathbf{o}} \mathrm{C}\end{array}$ \\
\hline 19.858 & 19.74 & 0.11 & 0.30 \\
29.686 & 29.70 & -0.02 & 0.30 \\
39.807 & 39.75 & 0.06 & 0.30 \\
\hline
\end{tabular}

Berdasarkan hasil kalibrasi, maka dapat dikatakan sensor suhu DS18B20 memenuhi persyaratan karena koreksi untuk masing masing set point masih berada dalam range $\pm 0.2^{\circ} \mathrm{C}$ sesuai standar WMO No. 08 [14].

Uji komunikasi LoRa $915 \mathrm{MHz}$ dilakukan di daerah tanpa penghalang. Jarak komunikasi yang dicoba yaitu jarak 200, 500, 1000, 1500, 2000 dan $2500 \mathrm{~m}$. Setiap jarak dilakukan 10 kali pengiriman data. Jumlah data yang diterima lalu dibuat dalam prosentase. 
Tabel 2. Hasil uji komunikasi LoRa $915 \mathrm{MHz}$

\begin{tabular}{cccc}
\hline $\begin{array}{c}\text { Jarak } \\
\mathbf{m}\end{array}$ & $\begin{array}{c}\text { Jumlah data } \\
\text { dikirim } \\
\mathrm{m}\end{array}$ & $\begin{array}{c}\text { Jumlah data } \\
\text { diterima } \\
\text { m }\end{array}$ & $\begin{array}{c}\text { Prosentase data } \\
\text { terkirim } \\
\%\end{array}$ \\
\hline 200 & 10 & 10 & 100 \\
500 & 10 & 10 & 100 \\
1000 & 10 & 9 & 90 \\
1500 & 10 & 9 & 90 \\
2000 & 10 & 7 & 70 \\
2500 & 10 & 5 & 50 \\
\hline
\end{tabular}

Hasil pengujian komunikasi menunjukan bahwa jarak komunikasi lebih dari 2500 $\mathrm{m}$ sudah tidak handal karena prosentase data hanya $50 \%$. Berdasar hasil pengujian maka dapat ditarik kesimpulan bahwa jarak $2000 \mathrm{~m}$ masih ideal dalam melakukan pengujian. Hasil pengujian masih mungkin terdapat perbedaan jika dilakukan di tempat pengujian dan keadaan lingkungan lain.

Pengujian Uji wahana dilakukan dua kali yaitu di bak air dan di waduk Situ Gintung. Uji wahana pertama dilakukan di bak air dengan merendam Buoyselama 24 jam untuk mengetahui kemungkinan kebocoran pada wahana Buoy. Hasil pengujian pertama menunjukan bahwa masih terdapat kebocoran minor pada titik fiberglas. Selanjutnya dilakukan pelapisan fiber ulang wahana Buoy agar tidak terdapat kebocoran. Setelah fiberglas kering maka dilakukan perendaman di bak air kembali. Hasil pengujian kedua ini menunjukan bahwa kebocoran sudah tertambal. Pengujian selanjutnya berpindah ke waduk situ Gintung Ciputat. Pengujian di waduk Situ Gitung dilakukan untuk mengetes titik kestabilan Buoy. Hasil pengujian menunjukan bahwa Buoysudahmengambang tegak lurus dan tidak terbalik.

\section{Kesimpulan}

Wahana Buoy yang telah dirancang dapat teruji mengapung dengan baik di perairan. Komunikasi LoRa menunjukan bahwa komunikasi berhasil mengirim data ke penerima yang berjarak $2000 \mathrm{~m}$ dengan kondisi tanpa penghalang. Hasil kalibrasi sensor suhu DS18B20 menunjukan koreksi masih berada dalam batas yang diperbolehkan yaitu $\pm 0.2^{\circ} \mathrm{C}$. Selain itu sensor suhu DS18B20 juga cocok jika diaplikasikan untuk mengukur SPL karena memiliki bersifat waterproof.

\section{Ucapan terima kasih}

Terima kasih sebesar besarnya penulis sampaikan kepada bapak Agus Tri Sutanto selaku Kepala Program Studi Instrumetasi STMKG. Ucapan terima kasih juga 
penulis sampaikan kepada bapak Hariyanto yang telah memberikan bimbingan atas perancangan wahan Buoyini. Tidak lupa penulis sampaikan terima kasih kepada rekan rekan Instrumentasi STMKG yang telah membantu dalam perancanganmaupun pengujian.

\section{Daftar Pustaka}

1. T. Kusumastanto, Pemberdayaan Sumberdaya Kelautan, Perikanan dan Perhubungan Laut dalam Abad XXI, Pusat Kajian Sumberdaya Pesisir dan Lautan,2003, Institut Pertanian Bogor.

2. EPA, Climate Change Indicators in the United States: Sea Surface, 2016

3. E. Rudi, Pemutihan Karang di Perairan Laut Natuna Bagian Selatan tahun 2010. Biospecies, Vol. 5 No. 1 (2012).

4. H.P. Hutagalung, Pengaruh Suhu Terhadap Kehidupan Organisme Laut, Pewarta Oseana, LON-LIPI, Jakarta, 13 (1988) pp.153-163.

5. E. Mulyana, Hubungan Antara Anomali Suhu Permukaan Laut dengan Curah Hujan di Jawa, Jurnal Sains \& Teknologi Modifikasi Cuaca, Vol. 1 No 2 (2000) pp.125-132.

6. J.R. Bidlot, D. J. Holmes, P.A. Wittmann, R. Lalbeharry, H.S. Chen, Intercomparison of the performance of operational ocean wave forecasting systems with Buoy data. Weather and Forecasting, Vol. 17 No. 2 (2002) p. 287-310.

7. M.A. Baqiya, T. Heriyanto, D. Kurniawan, M. Anwar, Darminto, Jurnal Sains Materi Indonesia, 102 - 105, Oktober 2007.

8. Resolution DP. 1-Wire Digital Thermometer. Data Sheets. DALLASMAXIM.[dostęp 11-07-2006]. Dostępny w Internecie: http://www. maximic. com/quick_view2. cfm/qv_pk/2813. 2008.

9. N. Sornin, $\bar{M}$. Luis, T.Eirich, T. Kramp, O. Hersent, Lorawan specification. LoRa alliance. 2015 Jan.

10. Oceanor, Seawatch Indonesia, An Introduction System to Sea Monitoring.1996.

11. D. Hastuti, P. U. Firdianto, Y. H. Pribadi, Penentuan Variabilitas Awan Menggunakan Satelit Himawar-8 di Bandara Tunggulwulung sebagai dampak Fenomena Siklon Tropis Cempaka, Jurnal Ilmu dan Inovasi Fisika Vol. 02 No. 02 (2018) p. 49-58.

12. S. Sitorus. N. Permana, A. P. Prasetyo, H. A. Larasati, Pemantauan Suhu Permukaan Laut Mengunakan Buoy Telemetri, Proseding Seminar Nasional Fisika dan Aplikasinya 2016, FINS-05-p107-114.

13. M. Iqbal, I. Jaya, M Purba, Rancang bangun dan uji kinerja drifter Buoy. Jurnal Teknologi Perikanan dan Kelautan, Vol. 2 No. 1 (2017) p.57-70.

14. C. A. Trasviña-Moreno, R. Blasco, A. Marco, R. Casas, A. Trasviña-Castro, Unmanned aerial vehicle based wireless sensor network for marine-coastal environment monitoring. SensorsVol. 17 No. 3 (2017) p.460.

15. World Meteorolgical Organization (WMO), Guide to Meteorological Instruments and Methods of Observation, Update in 2017, WMO no.08. Secretariat of the World Meteorological Organisation, Geneva, 2014 